\title{
Determinação da potência interferente versus a distância da estação LTE na TV Digital
}

\author{
Bruno Rodrigues Ferraz Izario e Cristiano Akamine
}

Resumo-Este trabalho tem por objetivo analisar a interferência entre o sistema LTE (Long Term Evolution) e ISDBTB (Integrated Services Digital Broadcasting Terrestrial version B) na banda de $700 \mathrm{MHz}$.

Para a análise é determinada a distância mínima que assegura o funcionamento dos dois sistemas na gama de funcionamento. $O$ impacto da interferência é avaliado em um cenário onde a estação de LTE, estação de TV digital e receptor de TV digital estão presentes na mesma área de cobertura.

Usando os parâmetros apresentados neste trabalho é calculado a potência de interferência que chega ao receptor de TV digital de acordo com a distância da estação de LTE e receptor de TV digital.

Além disso, o resultado também mostra que o filtro utilizado no receptor atenua a energia do sinal de LTE, e a distância entre a estação e o receptor de TV digital LTE diminui consideravelmente, o que permite uma interação entre os sistemas.

Palavra Chave-LTE, 4G, ISDB-TB, Interferência, 700 MHz.

Abstract- This work aims to analyze the interference between the LTE system (Long Term Evolution) and ISDB-T $T_{B}$ (Integrated Services Digital Broadcasting Terrestrial version B) in the $700 \mathrm{MHz}$ band.

For analysis, the minimum distance is determined which ensures the operation of two systems in the operating range. The interference impact is evaluated in a scenario where the LTE station, digital TV station and digital $T V$ receiver are present in the same coverage area. Using the parameters addressed in this paper, the interference power which arrives at the digital $T V$ receiver is calculated according to the distance between the LTE station and the digital TV receiver.

Furthermore, the result also shows that the filter used in the receiver attenuates the energy of LTE signal, and the distance between the station and the LTE digital TV receiver decreases considerably, permitting an interaction between the systems.

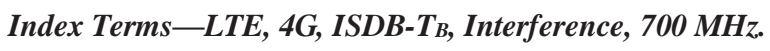

\section{INTRODUÇÃO}

Com a digitalização dos serviços de radiodifusão, a faixa de frequência de $700 \mathrm{MHz}$ será liberada permitindo com que o sistema de telefonia móvel ocupe tal área do espectro.

Atualmente, o Brasil encontra se na fase de convívio entre os sistemas analógico e digital e planeja desativar a transmissão analógica a partir de 2015 e pretensão de finalização em 2018 [1].

O uso da faixa escolhida para implantação dos serviços móveis é importante, a frequência permite, entre outras características, um menor número de estações rádio base, o que mostra interesse para países em desenvolvimento que possuem grandes áreas com densidade populacional pequena.

Discussões sobre o convívio do sistema LTE (Long Term
Evolution) e TV digital ocorrem. Porém, a preocupação dos radiodifusores e telefonia quanto a interferência de um sistema no outro é válida, apesar da Agência Nacional de Telecomunicações (ANATEL) impor regras para a integração e operação dos sistemas no Brasil.

Características eletromagnéticas na faixa de $700 \mathrm{MHz}$ permitem com que as ondas possibilitem maior raio de cobertura e uma robustez no sinal, quando comparado com as frequências mais elevadas.

Vários estudos foram realizados sobre a convivência entre o sistema LTE e TV digital. Em [2], a interferência da TV digital no LTE é estudada tendo como conclusão que a interferência maior ocorre quando o sistema interferido realiza o uplink.

Em [3], o estudo mostra a interferência do sistema LTE operando em canal adjacente ao da TV digital, sendo levado em consideração as torres de transmissão situadas em grandes distâncias, as conclusões foram semelhantes às encontradas em [2].

Em [4-9], são apresentados testes realizados em laboratório e campo a fim de estudar a interferência entre os sistemas LTE

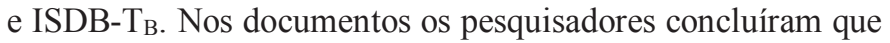
ao se implantar o sistema LTE em um canal adjacente ao da TV digital, algumas precauções para proteger os receptores em ambos os sentidos de transmissão, downlink e uplink, devem ser tomadas.

Na Tabela 1 e Tabela 2 são apresentados resultados de [9]. Estes valores contribuem para o resultado deste artigo.

\begin{tabular}{|c|c|c|}
\hline \multirow{2}{*}{ Canal } & \multicolumn{2}{|c|}{ Estação Rádio Base LTE } \\
\cline { 2 - 3 } & PR Medido (dB) & PR' Corrigido (dB) \\
\hline 38 a 45 & -55 & -50 \\
\hline 47 a 50 & -38 & -38 \\
\hline 51 & -37 & -37 \\
\hline $\begin{array}{c}\text { Demais canais } \\
\text { UHF }\end{array}$ & -58 & -51 \\
\hline
\end{tabular}

Tabela 2: Resultado do limiar de saturação em [9].

\begin{tabular}{|c|c|}
\hline Limiar de saturação & Terminal Móvel LTE \\
\hline Oth $(\mathrm{dBm})$ & -29 a 7 \\
\hline
\end{tabular}

Em [10], o estudo compara três metodologias para avaliar a frequência mínima de separação, a MCL (Minimum Coupling Loss), E-MCL (Enhanced Minimum Coupling Loss) e a Monte Carlo. Cada uma das metodologias tem suas vantagens e desvantagens. A escolha apropriada depende dos critérios utilizados e da ferramenta disponível para análise. Em níveis de complexidade o MCL é o mais simplista, abordando apenas um único interferente e vítima. Como resultado, o método Monte 
Carlo expressa resultados favoráveis, porém o grau de dificuldade para análise comparado aos outros dois métodos é alto. Dependendo do cenário analisado o E-MCL provê resultados significantes para análise.

Complementando os trabalhos citados, este artigo tem como objetivo determinar a distância de separação para a convivência dos sistemas LTE e ISDB- $\mathrm{T}_{\mathrm{B}}$, visando garantir o funcionamento destes sistemas sem interferência entre ambos, ou que o nível de potência interferente seja o mínimo aceitável para a configuração escolhida.

Para análise uma ferramenta foi desenvolvida possibilitando que alguns parâmetros sejam configurados tanto para o LTE como para o ISDB- $\mathrm{T}_{\mathrm{B}}$, o resultado é expresso de forma gráfica.

Este artigo está organizado da seguinte forma: A Seção II, fornece uma visão do LTE operante em 700 MHz. Na Seção III, é apresentado o ISDB-T $\mathrm{B}$. Na Seção IV é abordado o conceito de interferência de radiofrequência. Na Seção V são mostrados os parâmetros utilizados para o cálculo da distância de convivência entre o LTE e ISDB-T IS $_{B}$ através do software LB Network, além do resultado gráfico para os parâmetros escolhidos. Finalmente, a conclusão e trabalhos futuros são apresentados na Seção VI.

\section{LTE - LONG TERM EVOLUTION}

A $4^{\mathrm{a}}$ geração da telefonia móvel tem início com a tecnologia LTE e é gerenciada pelas normas estabelecidas no grupo 3GPP (3rd Generation Partnership Project). O sistema está operante em diversos países, sendo que no Brasil o mesmo já está sendo implantado com suas limitações e em diferentes frequências [11].

O padrão LTE chama a atenção pelas velocidades com as quais se pode trabalhar; dependendo da combinação de recursos implementados na rede e do aparelho do usuário, pode-se chegar a taxas de 300 Mbps para downlink e 75 Mbps para uplink, porém essas taxas ainda não foram implementadas [12].

Existem uma série de fatores que determinam as taxas em rede LTE: a quantidade de antenas em uso de maneira simultânea MIMO (Multiple-input multiple-output), a largura de banda canal que, quanto maior a largura de banda disponível, maior é a taxa de transferência de dados, a frequência de operação, a modulação usada e técnicas de correção de erro.

O LTE também se diferencia pela forma de acesso. Enquanto as tecnologias legadas são baseadas no padrão W-CDMA (Wideband Code Division Multiple Access), o LTE utiliza as especificações OFDMA (Orthogonal Frequency Division Multiple Access), que distribui as informações das transmissões entre diversos subconjuntos paralelos de portadoras, sendo este outro aspecto que favorece velocidades maiores para o downlink [13].

Para o uplink, o LTE utiliza o SC-FDMA (Single Carrier Frequency Division Multiple Access) que é uma especificação semelhante ao OFDMA, mas que consegue reduzir o consumo de potência, fazendo com que o gasto de energia por parte dos dispositivos conectados também diminua. Apesar do nome, o SC-FDMA também pode utilizar subconjuntos de portadoras [14].

\section{A. Arquitetura da Rede e de Protocolos}

A arquitetura escolhida para a tecnologia $4 \mathrm{G}$ é a EPS (Evolved Packet System), que é modelada para permitir a integração com outras redes de comunicação baseadas no protocolo IP. Essa tecnologia também permite conectividade com outras formas de acesso, tanto as padronizadas pelo 3GPP como as de banda larga fixa, como a DSL (Digital Subscriber Line).

A rede utilizada no LTE é considerada mais simples do que as utilizadas em redes anteriores, uma vez que os pacotes são processados e gerenciados no núcleo EPC (Evolved Packet Core). Esse processo produz respostas mais rápidas, melhorando a taxa de transmissão e o tempo de latência [15].

Uma característica comum em redes sem fio é a rápida variação na taxa de transmissão de dados, ocasionada pelas características do meio de transmissão e fenômenos climáticos. A fim de contornar esse obstáculo, a arquitetura EPS faz uso de retransmissão no eNodeB para gerenciar tal variação, onde adota algoritmos de controle de fluxo de dados no núcleo principal da arquitetura EPC que auxiliam na redução da perda de pacotes [16].

Através da utilização dos protocolos IP na arquitetura, a transmissão de vídeo em alta definição é possível, já que o sistema tem características para operar em tempo real e permite sincronizações entre os dispositivos interconectados, o que favorece uma maior qualidade de serviços.

Diferente dos outros releases ocorrentes no $3 \mathrm{GPP}$, no LTE, a arquitetura de rede tem 4 grandes domínios conforme nota-se na Figura 1 que é explicada na sequência.

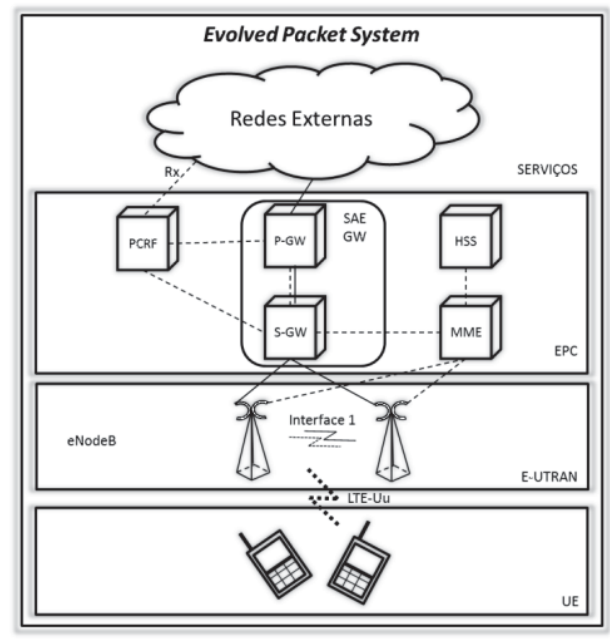

Figura 1: Arquitetura básica LTE EPS [17].

a) UE - User Equipment;

b) E-UTRAN - Evolved UMTS Terrestrial Radio Access Network;

c) EPC - Evolved Packet Core Network;

d) Serviços.

As grandes diferenças podem ser verificadas na E-UTRAN e no EPC. Na E-UTRAN, tem-se a remoção RNC (Radio Network Controller). De fato, a E-UTRAN é composta de uma rede MESH de eNodeBs que se comunicam através da interface 1 mostrada na Figura 1. No EPC existem diversos 

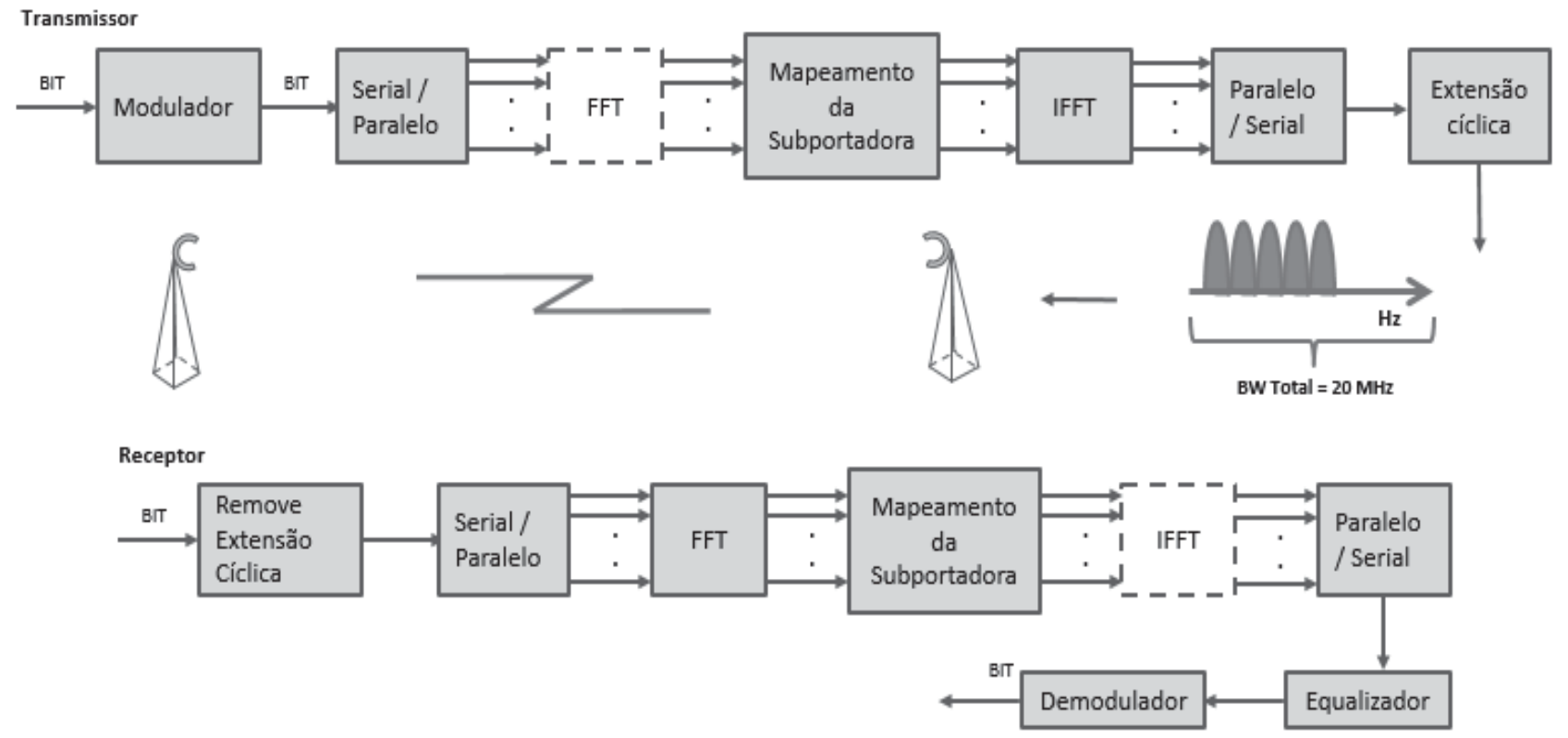

Figura 2: Transmissor e Receptor OFDMA e SC-OFDMA [18].

equipamentos, como: MME (Mobility Management Entity), SGW (Serving Gateway), HSS (Home Subscriber Server), P-GW (Packet Data Network Gateway) e PCRF (Policy and Charging Resource Funcion) [17].

A 3GPP teve como premissas iniciais simplificar a arquitetura de protocolos, extinguir os canais dedicados com o objetivo de se obter uma camada MAC (Media Access Control) simplificada e evitar a existência de funções similares entre os elementos de acesso e os elementos centrais da rede.

Os canais lógicos no sistema proveem os serviços e funções requisitados pelas altas camadas NAS (Non Access Stratum) para a entrega de aplicações e serviços. Os canais lógicos por sua vez, são mapeados pelos canais de transporte na camada 2 , através de elementos RRC (Radio Resource Control).

Os canais da interface rádio no LTE podem ser separados em dois tipos, canais físicos e sinais físicos. Os canais físicos correspondem a um conjunto de elementos que carregam informações originadas pelas altas camadas NAS. Os sinais físicos correspondem a um conjunto de elementos utilizados unicamente pela camada física, que não carregam informações originadas pelas altas camadas.

\section{B. OFDMA e SC-FDMA}

A tecnologia OFDMA transmite no domínio da frequência em diversas subportadoras paralelamente, o que no domínio do tempo, correspondem a múltiplas ondas senoidais com diferentes frequências. O OFDMA será utilizado apenas para enlace direto no sistema LTE, ou seja, para downlink.

Algumas características importantes no OFDMA são o excelente desempenho do OFDMA em canais com presença de fading seletivo em frequência, a baixa complexidade do receptor banda base e a compatibilidade com receptores avançados e novas tecnologias de antenas.

O conjunto de múltiplas subportadoras são independentes quanto a modulação, e no LTE elas podem ser moduladas em QPSK, 16-QAM ou 64-QAM.

Apesar de o OFDMA atender aos requisitos de downlink, suas propriedades não são recomendáveis para o uplink, principalmente devido ao desvanecimento do parâmetro chamado PAPR (Peak to Average Power Ratio).

O motivo para a utilização do SC-FDMA é o consumo de bateria do móvel. Sabe-se que o consumo de potência é algo fundamental para o handset sendo que, na estação rádio base o consumo de potência é algo fácil de ser controlado.

$\mathrm{O}$ transmissor e o receptor SC-FDMA são muito semelhantes aos da modulação OFDMA, a única diferença é a existência de uma FFT no transmissor SC-FDMA e uma IFFT no receptor SC-FDMA; por esta razão a modulação SC-FDMA é, muitas vezes, referida como frequency-spread OFDMA ou FFTspread OFDMA.

No sinal SC-FDMA, cada subportadora utilizada para transmissão contém informação de todos os símbolos modulados transmitidos. Em contrapartida, cada subportadora com um sinal OFDM carrega informações relacionadas a um símbolo específico.

A Figura 2 mostra o transmissor e o receptor para o SCFDMA, e desconsiderando os blocos tracejados é possível ter o diagrama do OFDMA.

\section{Frequência LTE $700 \mathrm{MHz}$}

Devido ao comportamento físico de operação dos meios eletromagnéticos, é notório que entre as frequências escolhidas o LTE possui uma maior cobertura na faixa de $700 \mathrm{MHz}$. Porém, a faixa de $700 \mathrm{MHz}$ ainda não está sendo utilizada no Brasil, apesar de já leiloada. Esta implantação com as mitigações necessárias só ocorrerá com o fim da transição da TV aberta analógica para a digital, fato este que deve ocorrer a partir de 2015 até 2018.

De acordo com a resolução da ANATEL n ${ }^{\circ}$ 625, de 11 de novembro, 2013 - as condições de uso de radiofrequências na faixa de $700 \mathrm{MHz}$ - relata que a nova destinação da faixa aos serviços de telecomunicações está internacionalmente harmonizada. O Brasil adotará o arranjo definido na Recomendação ITU-R (International Telecommunication 
Union - Radiocommunication) que permite o uso de $90 \mathrm{MHz}$ (45+45 MHz) por serviços de telecomunicações, com ganhos de escala associados ao uso de infraestrutura e terminais produzidos em escala global [16]. Os canais correspondentes a faixa homologada pela ANATEL inicia-se em 52 e termina em 69.

Na Resolução $n^{\circ}$ 640, de 11 de julho de 2014, que aprova o regulamento sobre as condições de convivência entre os serviços de radiodifusão de sons e imagens, de retransmissão de televisão do SBTVD e os serviços de radiocomunicação operando na faixa de $700 \mathrm{MHz}$, é destacado que os transmissores e receptores terão que possuir filtros abruptos capazes de ceifar as frequências interferentes, a largura de faixa ocupada não deve causar interferências prejudiciais entre blocos adjacentes, além do que a potência deve ser a mínima necessária para atender com boa qualidade e confiabilidade os serviços necessários. Apresenta também as técnicas de mitigação que serão utilizadas e os casos que são considerados interferências prejudiciais [19].

\section{SBTVD - Sistema BRASILEIRO DE TElEVISÃo Digital}

A TV digital está sendo implantada para substituir a TV analógica. Após o término das transmissões analógicas, os telespectadores serão obrigados a adquirir televisores com receptor digital integrado ou conversores do sinal digital (settop-box) em analógico para que possam usufruir da tecnologia e seus recursos de interação.

Além da boa qualidade dos sinais de áudio e vídeo, a TV digital, permite um uso mais eficiente do espectro eletromagnético [20].

O sistema de TV digital é composto por um conjunto de padrões que compõem a codificação de áudio e vídeo e que representa o serviço essencial transmitido na TV, sendo alguns novos, como a interatividade

O sistema de transmissão e recepção da TV digital é apresentado, respectivamente, nas Figura 3 e Figura 4, porém existem seguimentos implementados neste padrão que são adotados por outros sistemas de modo a permitir um modelo de TV digital com características diferenciadas.

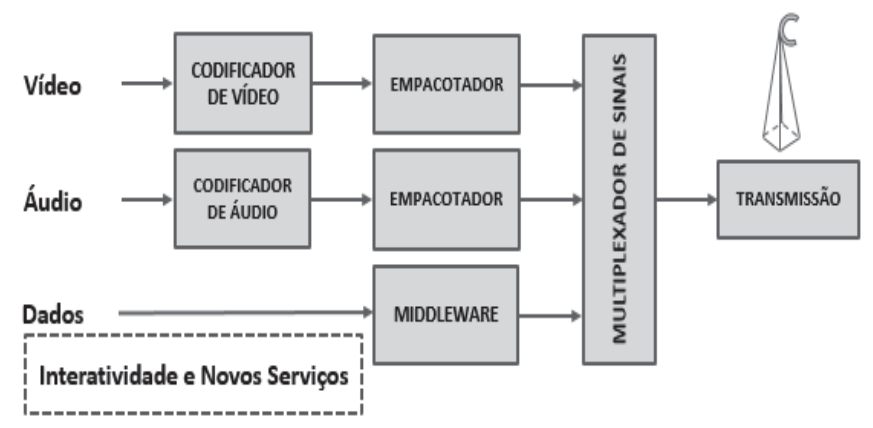

Figura 3: Padrão básico de transmissão da TV digital [20].

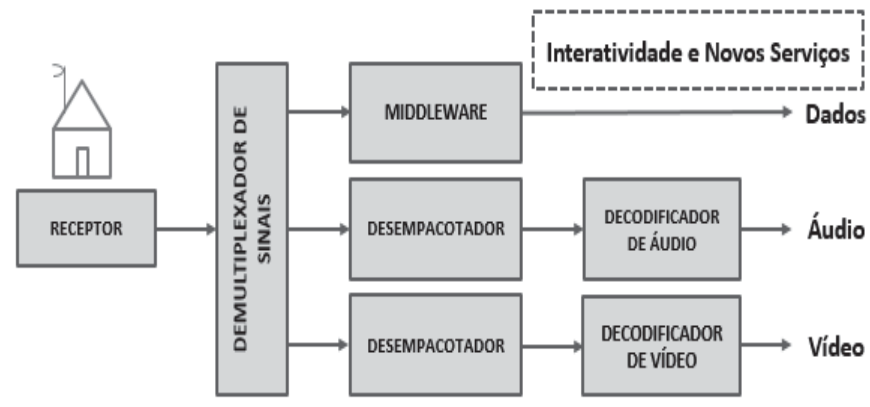

Figura 4: Padrão básico de recepção da TV digital [20].

Para os sistemas de TV digital a técnica de modulação usada na transmissão é a principal característica. No geral são usadas duas técnicas: a SCM (Single-Carrier Modulation) e a MCM (Multi-Carrier Modulation). Dessa forma, cada técnica de modulação causa diferentes comportamentos do sinal no canal, considerando também as diferenças no processo de codificação do sinal. Existem em operação cinco modelos ou padrões da TV digital terrestre no mundo [21]:

a) ATSC (Advanced Television System committee);

b) DVB-T (Digital Video Broadcasting - Terrestrial);

c) ISDB-T/B (Integrated Services Digital Broadcasting Terrestrial/version B);

d) DTMB (Digital Terrestrial Multimídia Broadcast);

e) DVB-T2 (Digital Video Broadcasting Terrestrial Second Generation).

O sistema adotado no Brasil é ISDB- $\mathrm{T}_{\mathrm{B}}$, também conhecido por o SBTVD (Sistema Brasileiro de TV Digital) que foi desenvolvido a partir do padrão Japonês ISDB-T. Todo o sistema de transmissão e recepção é normalizado pela ABNT NBR 15601 - 15608, porém as técnicas utilizadas e os algoritmos podem variar de acordo com o desenvolvedor [21].

No ISDB-T I $_{\mathrm{B}}$ os sinais são transmitidos usando a modulação BST - OFDM (Band Segmented Transmission - Orthogonal Frequency-Division Multiplexing) que além de garantir uma melhor robustez comparada com outros padrões, tem a característica da banda segmentada, que permite a flexibilidade de diferentes tipos de serviços em um canal de $6 \mathrm{MHz}$. Para a compressão do vídeo, o padrão H.264, sendo a compressão de áudio feita pelo MPEG-4 AAC.

Diferente do sistema analógico, a transmissão do áudio e do vídeo passa a ser feita através de sinais digitais que, codificados e comprimidos, permitem um uso mais eficiente do espectro, devido ao aumento da taxa de transmissão de dados na banda de frequências disponíveis.

\section{A. Sistema de Modulação ISDB-T}

O sistema de modulação ISDB- $\mathrm{T}_{\mathrm{B}}$ pode ser dividido em três estágios compostos pelo remultiplexador, codificador de canal e modulador, como pode ser visto na Figura 5. 


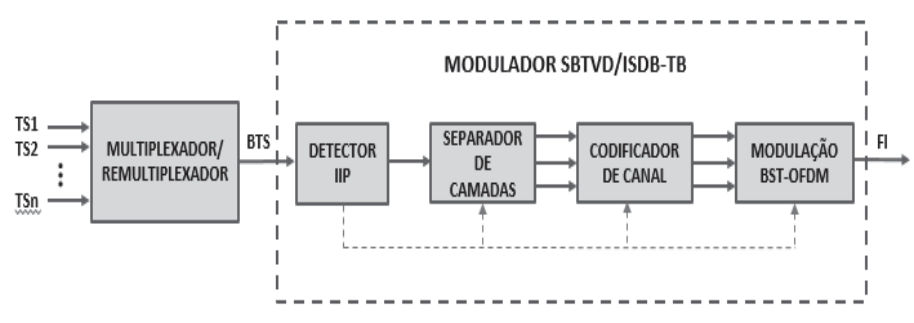

Figura 5: Diagrama simplificado do Modulador [22]

Os sistemas de multiplexação e remultiplexação são responsáveis pela geração do BTS (Broadcast Transport Stream). Em primeiro lugar, o sinal comprimido de áudio, vídeo, dados e tabelas de sistema devem ser multiplexados. Em seguida, informações sobre os parâmetros de modulação e sincronismo são inseridas no bloco chamado de remultiplexador [22].

Após o sinal contendo toda informação multiplexada o processo de codificação de canal inicia com a detecção do IIP (ISDB-T information Packets), na sequência o separador de camadas tem a finalidade de direcionar cada TPS (Transport Packets Stream) do BTS à sua respectiva camada, tendo como saída um MPEG-2 TS.

O estágio de codificação é dividido por um bloco de codificação externa e interna. $\mathrm{O}$ estágio de codificação externa é formado por um codificador Reed Solomon com entrelaçador de bytes. O estágio de codificação interna é formado pelo codificador convolucional de $1 / 2 \mathrm{com}$ ajuste de puncionamento para $1 / 2,2 / 3,3 / 4,5 / 6,7 / 8$ com entrelaçamento de bits e símbolos. É na codificação que o sinal MPEG-2 TS recebe redundância de forma a garantir robustez para o sinal a ser transmitido de maneira a permitir que na recepção o sinal seja decodificado [22].

No terceiro estágio o sinal é modulado em QPSK, 16-QAM ou 64-QAM, depois uma estrutura de sincronismo é adicionada com a inserção de pilotos de referência, sinalização e controle. Após esta primeira etapa de modulação o sinal passa por um modulador BST-OFDM que opera com IFFT de tamanho $2 \mathrm{k}$, $4 \mathrm{k}$ ou $8 \mathrm{k}$. Na saída do modulador OFDM é adicionado um prefixo cíclico que garante a robustez do sistema contra interferência intersimbólica. Os sinais em FI são convertidos para analógico em banda básica ou frequência intermediária de $44 \mathrm{MHz}$ [20].

\section{B. BST-OFDM}

Cada segmento utiliza uma largura de banda correspondente a $6 / 14 \mathrm{MHz}(428,57 \mathrm{kHz})$ como pode ser visto na Figura 6 [22].

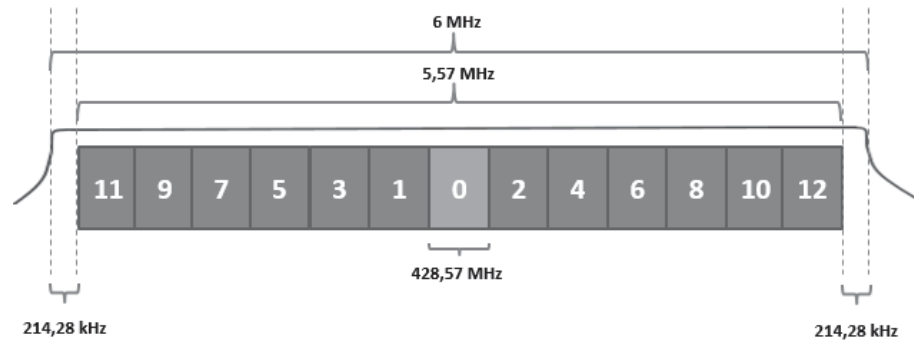

Figura 6: Divisão da Banda de 6 MHz em 13 segmentos mais banda de guarda [23].
Esses 13 segmentos podem ser combinados em até três camadas hierárquicas diferentes, que lhe conferem maior ou menor robustez, dependendo da aplicação a que se destinam. Um desses segmentos é reservado à transmissão para receptores móveis e portáteis, tais como celulares e notebooks, com parâmetros de transmissão adequados a essa aplicação. Ao mesmo instante de tempo e canal, os outros 12 segmentos podem ser utilizados para transmissão em alta definição para receptores fixos.

No Brasil, a maioria dos radiodifusores utilizam duas camadas: 1 segmento para a recepção em terminais portáteis ou telefones celulares (One-Seg) e 12 segmentos para recepção fixa (HDTV).

\section{Sintonizadores}

O sintonizador é o elemento que sintoniza um canal de TV, filtra sinais indesejáveis, amplifica/atenua o sinal de RF e realiza a translação do mesmo para uma frequência intermediária. Em alguns modelos, o sintonizador realiza a demodulação em quadratura (banda-base).

Existem dois tipos de sintonizadores usados em receptores de TV digital: Can tuners e Silicon tuners. Diferem quanto ao desempenho e, consequentemente, custo devido a sua composição e fabricação.

Sintonizadores do tipo Can tuners utilizam sintonizadores super-heteródinos tradicionais, formados por componentes discretos dentro de um encapsulamento de metal para minimizar as interferências externas [9].

Os Silicon tuners são baseados em circuitos integrados, conectados a uma placa principal. Esses circuitos integrados podem ter uma cobertura metálica para proteção contra interferências [9].

Após o estágio de sintonia, é realizada a demodulação em circuitos integrados específicos que recuperam o transport stream.

\section{Espectro da Radiodifusão}

$\mathrm{O}$ espectro destinado para transmissão da TV terrestre no Brasil abrange as faixas de VHF e UHF. O VHF Baixo e Alto corresponde as frequências de 54 - $88 \mathrm{MHz}$ (canais 2 - 6) e 174 - $216 \mathrm{MHz}$ (canais 7-13).

A faixa de UHF (470 MHz - $806 \mathrm{MHz}$ ) abrange os canais 14 a 69. Na faixa de $700 \mathrm{MHz}$ estão presentes os canais da TV analógica/digital que serão extintos e realocados para aplicação da radiodifusão e telefonia móvel. Os canais, 50 e 51 são motivos de estudo devido a interferência co-canal existente.

A partir das Equações 1, 2 e 3 é possível calcular a frequência central do VHF baixo, VHF alto e UHF respectivamente.

$$
\begin{array}{ll}
F_{\mathrm{VHF} \_ \text {Baixo }}=57+(n-2) \times 6 & {[\mathrm{MHz}]} \\
F_{\mathrm{VHF} \_ \text {Alto }}=177+(n-7) \times 6 & {[\mathrm{MHz}]} \\
F_{\mathrm{UHF}}=473+(n-14) \times 6 & {[\mathrm{MHz}]}
\end{array}
$$

onde,

$n$ - Número do canal desejado para cada faixa de frequência. 


\section{INTERFERÊNCIA DE RADIOFREQUÊNCIA}

Interferência é qualquer emissão, radiação ou indução que modifique, obstrua ou interrompa repetidamente um sistema de comunicação, operando de acordo com os procedimentos, normas e regulamentos aprovados pelo órgão regulamentador (ANATEL para o Brasil).

Os sinais interferentes são sinais de outras comunicações que adentram no canal em uso de modo a modificar o sinal original.

Nos sistemas de TV e de telefonia móvel, a interferência pode ser de natureza co-canal ou de canal adjacente.

A interferência co-canal ocorre quando duas ou mais emissoras atuam na mesma faixa de frequência, porém, em diferentes áreas de cobertura. Essa interferência geralmente surge quando, na instalação dos transmissores de TV ou das estações rádio bases não se respeitam as distâncias adequadas para o seu isolamento.

A interferência de canal adjacente ocorre quando duas emissoras que ocupam canais adjacentes transmitem sinais uma na faixa da outra, o que pode ser ocasionado quando imperfeições dos filtros nos receptores permitem a recepção de sinais indesejados, provenientes de faixas de frequências próximas, ou quando a potência mínima fora da banda não é respeitada.

O máximo nível de potência interferente aceito na entrada do receptor, Oth (Overload Threshold), foi apresentado em [9], sendo de $-26 \mathrm{~dB}$. Além do Oth, o parâmetro PR (Protection Ratio) é o valor mínimo da relação sinal desejado pelo interferente, sendo este necessário para manter a qualidade da recepção de TV. Para fins de parametrização, este artigo utilizará o PR igual a $-50 \mathrm{~dB}$ apresentado em [9].

A interferência resulta na degradação do sinal transmitido, danificando toda e qualquer informação transmitida, sendo ela voz, vídeo ou dados.

Vários são os problemas que podem ocasionar interferência nos sistemas, porém o presente estudo considera a interferência co-canal, a interferência gerada pelo canal adjacente e a interferência gerada pela potência de transmissão do LTE saturando o receptor de TV digital.

Para o caso estudado e diversas outras pesquisas a utilização de filtros bloqueadores se torna indispensável para o convívio dos sistemas TV digital e LTE atuando em canais adjacentes.

\section{Dimensionamento de ConvivênCia LTE e SBTVD}

Para projetar uma rede de radiodifusão ou de telefonia móvel, primeiramente, é necessário identificar quais as características que devem ser levadas em consideração para a otimização da rede. O objetivo é obter a maior cobertura com a menor quantidade de equipamento possível, e ao mesmo tempo prover a capacidade de rede necessária para se atender a demanda de usuários. Porém, se os dois sistemas estiverem operando na mesma faixa de frequência ou em canais adjacentes os cuidados no dimensionamento são ainda maiores. Problemas de interferência como descritos na Seção IV ocorrerão e regras concedidas pelo órgão responsável, a ANATEL no caso do Brasil, deverão ser respeitadas.

O planejamento da rede consiste em se obter informações como: a cobertura desejada, estimativas de tráfego por usuário, serviços a serem oferecidos, a qualidade de serviço requerida QoS (Quality of Service) e a capacidade necessária.

Para fins de dimensionamento faz-se necessário o cálculo de link budget. O software LB Network propicia realizar uma rede LTE calculando o número de estações rádio base necessárias para cobrir a área de interesse, sendo adotado como modelo de predição o SUI (Stanford University Interim). No entanto, este cálculo não é suficiente quando temos outro sistema na mesma região geográfica e que opera na mesma faixa de frequência.

Para que o LTE seja instalado seguindo os parâmetros de link budget e não interfira no sistema adjacente é possível calcular a distância necessária para o LTE de modo que seja respeitada a potência máxima permitida no receptor ISDB- $\mathrm{T}_{\mathrm{B}}$, ou seja, o telespectador da TV digital não terá seu sistema comprometido com a potência que chegará ao seu receptor gerada pelo sistema interferente.

As características básicas dos dois sistemas devem ser conhecidas. O LB Network calcula a perda de propagação levando em consideração a distância de atuação da célula, vide Equação 4.

$$
\mathrm{L}=\mathrm{A}+10 \times \alpha \times \log \left(\frac{d}{d_{0}}\right)+X_{f}+X_{h}+S
$$

onde,

$L$ - Máxima perda no modelo de propagação de SUI;

$A$ - Perda no espaço livre considerando a distância $\mathrm{d}_{0}$;

$\alpha$-Fator de perda do caminho em função da altura da estação rádio base;

$d$ - Distância ou raio máximo de atuação da célula [m];

$d_{0}$ - Distância de referência [m];

$X_{f}-$ Correção da frequência $[\mathrm{dB}]$;

$X_{h}-$ Correção da altura da antena receptora $[\mathrm{dB}]$;

$S$ - Desvanecimento de acordo com o tipo de Terreno [dB].

As Equações 5,6,7 e 8 são adendos a Equação 4, sendo o $\lambda$, na Equação 5, o comprimento de onda.

$$
\begin{aligned}
& \mathrm{A}=20 \times \log \left(\frac{4 \pi \times d_{0}}{\lambda}\right) \\
& \mathrm{X}_{f}=6 \times \log \left(\frac{f}{2000}\right) \\
& \mathrm{X}_{\mathrm{h}}=-10,8 \times \log \left(\frac{h}{2}\right) \\
& \mathrm{X}_{\mathrm{h}}=-20 \times \log \left(\frac{h}{2}\right) \\
& \alpha=a-b \times h_{b}+\frac{c}{h_{b}}
\end{aligned}
$$

onde,

$h$ - Altura da antena receptora $[\mathrm{m}]$;

$h_{b}$ - Altura da estação rádio base [m]; 


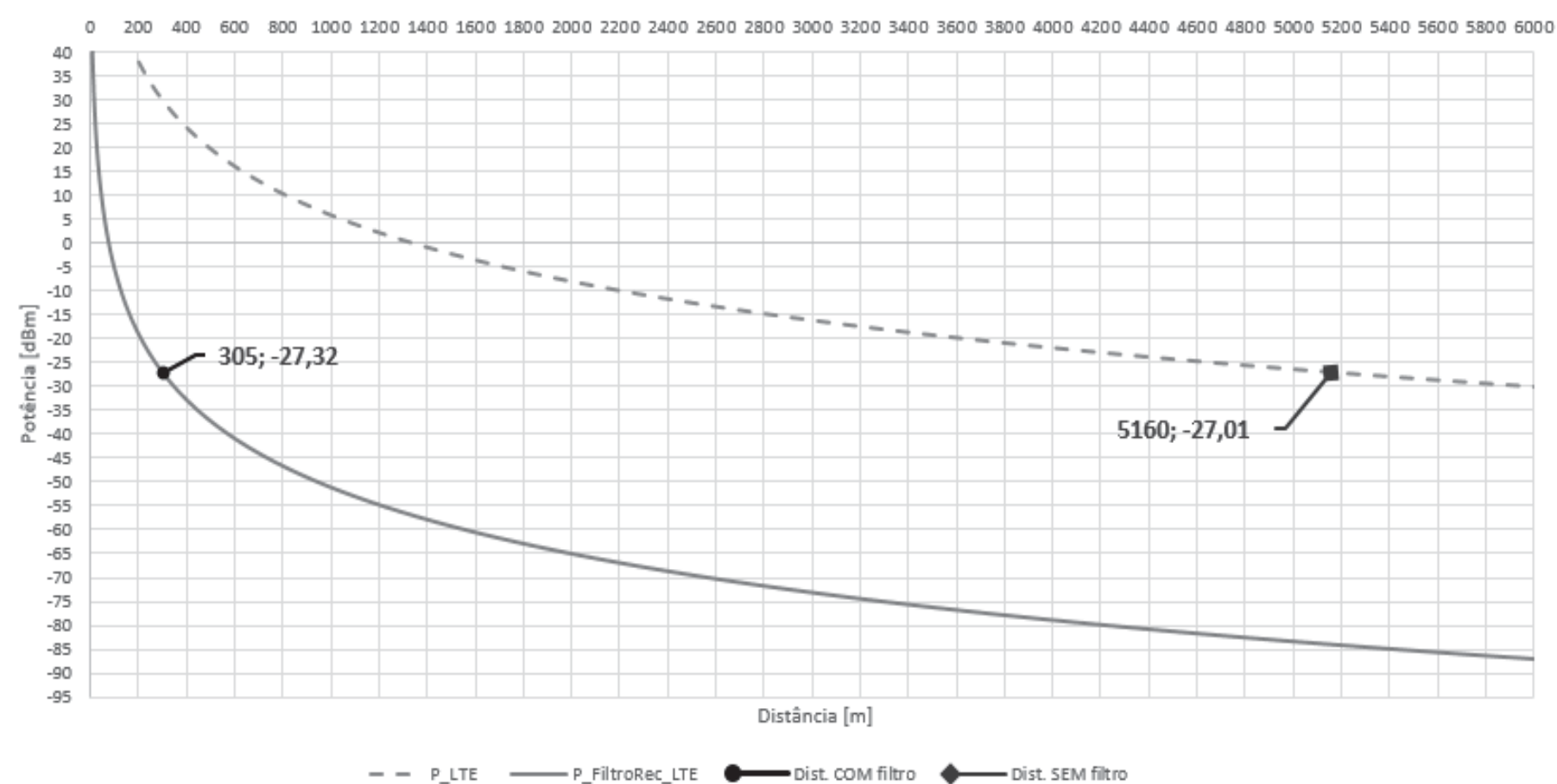

Figura 7: Gráfico da potência de interferência LTE em função da distância da estação rádio base LTE até o receptor da TV digital.

$a, b, c$ - Valores empíricos do modelo SUI para o tipo de relevo.

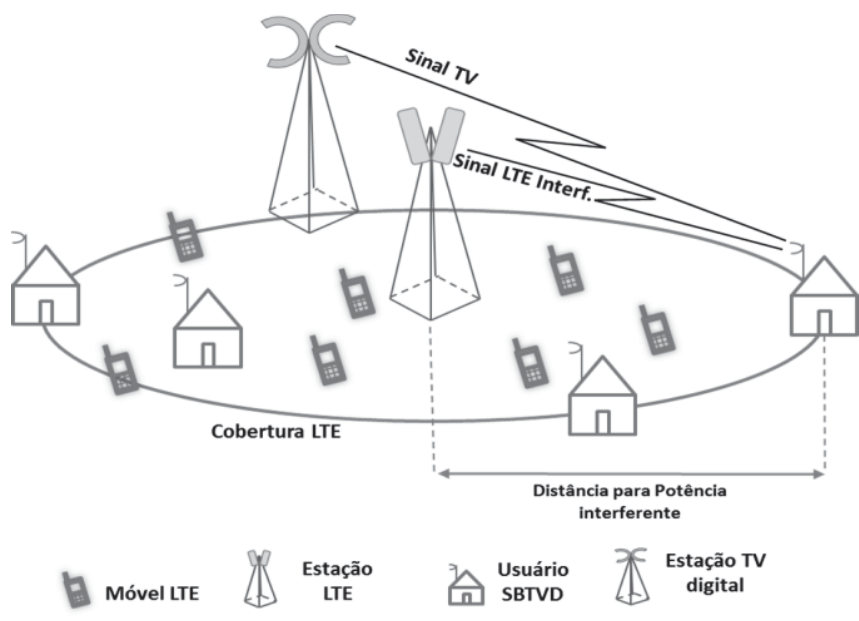

Figura 8: Cenário de convivência LTE e SBTVD.

Para o cenário da Figura 8, observa-se que o receptor de TV digital com antena externa recebe sinal da estação rádio base LTE e TV digital. Com os parâmetros da Tabela 3 é possível calcular o nível de potência interferente e estimar qual a distância necessária para não interferir o receptor TV digital.

Tabela 3: Parâmetros do Sistema LTE e TV Digital.

\begin{tabular}{|c|c|c|}
\hline Parâmetros LTE & Valor & Unidade \\
\hline Frequência central de Transmissão & 768 & $\mathrm{MHz}$ \\
\hline Potência de Transmissão & 46 & $\mathrm{dBm}$ \\
\hline Largura de Banda & 10 & $\mathrm{MHz}$ \\
\hline Ganho da Antena Transmissora & 14 & $\mathrm{dBi}$ \\
\hline Máscara da Estação Rádio Base & -26 & $\mathrm{~dB}$ \\
\hline
\end{tabular}

\begin{tabular}{|c|c|c|}
\hline Parâmetros TV digital & Valor & Unidade \\
\hline Ganho da Antena Externa & 12,7 & $\mathrm{dBi}$ \\
\hline Filtro do Receptor & -56 & $\mathrm{~dB}$ \\
\hline
\end{tabular}

O parâmetro filtro do receptor respeita os valores de atenuação da Tabela 4 de acordo com a frequência de transmissão.

Tabela 4: Valores de atenuação para um filtro comercial utilizado no receptor TV digital.

\begin{tabular}{|c|c|}
\hline \multicolumn{2}{|c|}{ Atenuação - Filtro do Receptor } \\
\hline Frequência Transmissão [MHz] & Atenuação [dB] \\
\hline$<680,0$ & $-1,47$ \\
\hline 686,0 & $-1,74$ \\
\hline 692,0 & $-2,25$ \\
\hline 698,0 & $-3,2$ \\
\hline 703,0 & $-5,0$ \\
\hline 708,0 & $-14,4$ \\
\hline 718,0 & $-27,3$ \\
\hline 748,0 & $-50,0$ \\
\hline$>758,0$ & $-56,0$ \\
\hline
\end{tabular}

Após projetada toda a rede LTE, é necessário configurar o LB Network com os parâmetros mencionados na Tabela 3.

Considerando a potência do sinal de TV Digital em $-77 \mathrm{dBm}$ e o parâmetro PR igual a $-50 \mathrm{~dB}$ [9], sabe-se que o nível de sinal interferente LTE deve ser menor que $-27 \mathrm{dBm}$.

A curva tracejada na Figura 7 mostra a potência LTE que chega no receptor da TV digital em função da distância que a estação rádio base está do receptor. Sem a presença do filtro no receptor, a distância mínima para que o sinal LTE não interfira na TV digital, de acordo com as considerações apresentadas em [9], é de $5,16 \mathrm{~km}$. 
Com a implementação do filtro no receptor digital, é possível observar que a distância da estação rádio base até o receptor diminuiu, sendo esta de $305 \mathrm{~m}$ de acordo com a curva contínua apresentada na Figura 7.

\section{CONCLUSÃO}

Para que toda a capacidade e desempenho das redes de telefonia móvel e radiodifusão sejam atendidas, o dimensionamento do projeto da rede deve ser corretamente estabelecido, a começar pela área de atuação de cada estação rádio base, decorrente do raio máximo de atuação de cada célula e sua capacidade de dados, além do controle de potência emitido fora da área de cobertura.

O resultado deste trabalho mostra que o LTE irá interferir no receptor da TV digital caso os dois sistemas operantes na faixa de $700 \mathrm{MHz}$ não forem dimensionados corretamente. Essa interferência torna-se prejudicial ao SBTVD a partir do momento que a potência máxima interferente é maior que a potência máxima aceita pelo receptor. Entretanto, o resultado obtido neste trabalho, aponta fatores que poderão influenciar no impacto da interferência do LTE no SBTVD. A largura de banda ocupada, a distância de separação entre os sistemas, o ganho da antena externa, a potência de transmissão do LTE e a máscara de bloqueio são parâmetros que devem ser controlados para que haja uma relação harmoniosa dos sistemas na faixa de $700 \mathrm{MHz}$.

A instalação de filtros nos receptores para o SBTVD visa aumentar a sua proteção contra as interferências, porém como pode ser observado na Tabela 4, a atenuação na banda passante é na ordem de $1 \mathrm{~dB}$, ou seja, haverá também uma atenuação do sinal da TV digital.

O telespectador pode, ou não, optar pela utilização do filtro o que acarretará em custo para o mesmo.

Apesar das divergências de operação dos dois sistemas, o resultado também mostra que é possível a coexistência da TV digital e telefonia móvel na faixa de frequências dos $700 \mathrm{MHz}$, desde que, as distâncias de separação e potência sejam administradas pelo órgão responsável e as operadoras de telefonia móvel e emissoras de TV respeitem as primícias.

Para trabalhos futuros, espera-se acrescentar no software LB Network outros parâmetros que influenciam na interferência de radiofrequência sendo que estas possam ser observadas como manchas em mapas de cobertura, além de implementar as torres de radiodifusão como um elemento interferente nos receptores do LTE, ou seja, o software ser capaz de estimar a interferência e suas mitigações para os dois sistemas de modo que um não interfira direta ou indiretamente no outro. Da mesma forma que em [10], o software poderá selecionar o melhor método para analisar vítima-interferente, de modo a garantir o melhor resultado quando comparado com resultados práticos.

\section{REFERÊNCIAS}

[1] Portaria $\mathrm{N}^{\circ} 481$ de 9 de Julho de 2014.

[2] Weidong Wang; Weidong Wang; Zhi Lv; Wei Huang; Yinghai Zhang, "Analysis of interference from digital Terrestrial Television Broadcast to LTE TDD in Digital Dividend spectrum, Network". 2nd IEEE International Conference on, Sept. 2010
[3] Wei Li; Jiadi Chen; Hang Long; Bin Wu, "Performance and Analysis on LTE System under Adjacent Channel Interference of Broadcasting System". IEEE 12th International Conference on, Oct. 2012.

[4] ANATEL, Relatório do Teste em Campo sobre a Convivência do LTE na faixa de $700 \mathrm{MHz}$ com ISDB-T. Abril,2014.

[5] ANATEL, Relatório de Teste Laboratorial de Interferência do LTE na faixa de $700 \mathrm{MHz}$ no ISDB-T. Abril, 2014.

[6] ABINEE, Projeto de Testes de coexistência entre o Sistema Brasileiro de Televisão Digital e o LTE na faixa de 700MHz (Banda 28 3GPP). Janeiro, 2014.

[7] ABINEE, Projeto de testes para avaliação de interferência e análise de coexistência entre o Sistema Brasileiro de Televisão Digital e o LTE na faixa de $700 \mathrm{MHz}$ (Banda 28 3GPP) - Teste Laboratorial. Abril, 2014.

[8] ABINEE, Projeto de testes para avaliação de interferência e análise de coexistência entre o Sistema Brasileiro de Televisão Digital e o LTE na faixa de $700 \mathrm{MHz}$ (Banda 28 3GPP) - Teste de Campo. Maio, 2014.

[9] SET; MACKENZIE, Testes de interferência do sinal LTE na recepção de TV digital na faixa de UHF. São Paulo-SP. Fevereiro,2014.

[10] ERC Report 101: "A comparison of the minimum coupling loss method, enhanced minimum coupling loss method, and the Monte-Carlo simulation", Menton, 1999.

[11] ABDUL, S. B. "Dimensioning of LTE Network - Description of Models and Tool, Coverage and Capacity Estimation of 3GPP Long Term Evolution radio interface", Februery 2009.

[12] SESIA, S.; TOUFIK, I.; BAKER, M. "LTE - The UMTS Long Term Evolution - From Theory to Practice". John Wiley \& Sons Ltd, 2009.

[13] DAHLMAN, E. et al. "3G evolution: HSPA and LTE for Mobile Broadband". Oxford, UK: Elsevier Ltd, 2007.

[14] Y., Bei, C. Joseph."LTE uplink MIMO receiver with low complexity interference cancellation", Analog Integrated Circuits and Signal Processing, 2012, Vol.73

[15] 3GPP, Tech. Specif. Group Radio Access Network - Physical Channels and Modulation, 3GPP TS 36.211, Dec. 2009.

[16] D’ÁVILA, César Kyn. "LTE: Long Term Evolution - Arquitetura Básica e acesso Múltiplo". 2009. Disponível em: http://www.cedet.com.br/index.php?/Tutoriais/Telecom/lte-long-termevolutionarquitetura-basica-e-acesso-multiplo.html

[17] ROHDE; SCHWARZ. UMTS Long Term Evolution (LTE) Technology Introduction, 2008

[18] S. MARTIN. "Beyond 3G - Bringing NetworkS, Terminals and the Web Together-LTE, WiMAX, IMS, 4G Devices and the Mobile Web 2.0". John Wiley \& Sons. 2009.

[19] RESOLUÇÃO Nº 640, DE 11 DE JULHO DE 2014 - Regulamento sobre condições de convivência entre os serviços de radiodifusão de sons e imagens e de retransmissão de televisão do SBTVD e os serviços de radiocomunicação operando na faixa de $698 \mathrm{MHz}$ a $806 \mathrm{MHz}$.

[20] Sistema de TV Digital. Revista Mackenzie de Engenharia e Computação, Ano 5, n. 5, p.13-96. Disponível em: www.mackenzie.br/fileadmin/Editora/Revista enge/introducao.pdf. Acesso em: março, 2015.

[21] ALENCAR, M. S. Digital Television. New York: Cambridge University Press, 2009

[22] AKAMINE, C. IANO, Y. Software de Simulação do Sistema de Modulação ISDB-TB. Revista de Rádio Difusão. Vol. 3, n. 3, p.297-307.

[23] ISHINI, A. K., AKAMINE, C. Técnicas de Estimação de Canal para o Sistema ISDB-TB. Revista de Rádio Difusão. Vol. 3, n. 3, p.151-157

Bruno Rodrigues Ferraz Izario Possui graduação em Engenharia de Telecomunicações pelo Instituto Nacional de Telecomunicações (2007-2011). MBA em gestão de Negócios pela Universidade Nove de Julho (2012) e cursa mestrado em Engenharia Elétrica pela Universidade Mackenzie (2013). Tem experiência na área de Elétrica/Telecomunicações, atuando em pesquisas com os seguintes temas: Antenas, Transmissão, Design de Redes e Rádio Frequência. Atualmente, trabalha na área de Comunicações Táticas na empresa SAVIS Embraer Defesa e Segurança implantando equipamentos de Rádio Frequência para o exército brasileiro.

Cristiano Akamine Possui graduação em Engenharia Elétrica pela Universidade Presbiteriana Mackenzie (1999), mestrado e 
doutorado em Engenharia Elétrica pela Universidade Estadual de Campinas (2004/2011). É pesquisador do Laboratório de TV digital da Universidade Presbiteriana Mackenzie desde 1998, realizou estágio no NHK Science and Technology Research Laboratories (STRL), possui várias patentes e diversos artigos publicados. É professor no curso de Engenharia Elétrica e do Programa de Pós-Graduação em Engenharia Elétrica e de Computação (PPGEEC) da Universidade Presbiteriana Mackenzie. Tem experiência na área de Engenharia Elétrica, com ênfase em TV digital, comunicação digital, codificação de canal, sistemas embarcados, lógica reconfigurável e rádio definido por software. Atualmente é Professor Especialista Visitante na Faculdade de Tecnologia da Unicamp e participante do programa de Pós-Graduação da Faculdade de Engenharia Elétrica e de Computação (FEEC) da Unicamp.

Cite this article:

Rodrigues Ferraz Izario, B, e Akamine, C.; 2015. Determinação da potência interferente versus a distância da estação LTE na TV Digital. SET EXPO PROCEEDINGS. ISSN Print: 2447-0481.ISSN Online: 2447-049X. v.1. doi: 10.18580/setep.2015.1.9 Web-link: http://dx.doi.org/10.18580/ setep.2015.1.9 